\title{
Oral Cannabidiol Prevents Allodynia and Neurological Dysfunctions in a Mouse Model of Mild Traumatic Brain Injury
}

OPEN ACCESS

Edited by:

Marialessandra Contino,

University of Bari Aldo Moro, Italy

Reviewed by:

Faramarz Dehghani,

Martin Luther University of Halle-Wittenberg, Germany

Joseph T. McCabe,

Uniformed Services University of the

Health Sciences, United States

*Correspondence:

Sabatino Maione

sabatino.maione@unicampania.it

Francesca Guida

franc.guida@gmail.com

${ }^{\dagger}$ These authors have contributed equally to this work

Specialty section:

This article was submitted to Experimental Pharmacology

and Drug Discovery,

a section of the journal

Frontiers in Pharmacology

Received: 19 December 2018 Accepted: 21 March 2019

Published: 16 April 2019

\section{Citation:}

Belardo C, lannotta $M$,

Boccella S, Rubino RC, Ricciardi F, Infantino $R$, Pieretti $G$, Stella $L$, Paino S, Marabese I, Maisto R, Luongo L, Maione $S$ and Guida F (2019) Oral Cannabidiol Prevents Allodynia and Neurological Dysfunctions in a Mouse Model of Mild Traumatic Brain Injury.

Front. Pharmacol. 10:352. doi: 10.3389/fphar.2019.00352
Carmela Belardo ${ }^{1 \dagger}$, Monica lannotta ${ }^{1+}$, Serena Boccella ${ }^{1 \dagger}$, Rosamaria Cristina Rubino ${ }^{2}$ Flavia Ricciardi ${ }^{1}$, Rosmara Infantino ${ }^{1}$, Gorizio Pieretti ${ }^{3}$, Luigi Stella ${ }^{4}$, Salvatore Paino ${ }^{1}$, Ida Marabese ${ }^{1}$, Rosa Maisto ${ }^{1}$, Livio Luongo ${ }^{1}$, Sabatino Maione ${ }^{1 *}$ and Francesca Guida ${ }^{\text {* }}$

${ }^{1}$ Department of Experimental Medicine, University of Campania Luigi Vanvitelli, Naples, Italy, ${ }^{2}$ Enecta s.r.l., Bologna, Italy, ${ }^{3}$ Department of Plastic Surgery, University of Campania Luigi Vanvitelli, Naples, Italy, ${ }^{4}$ Drug Addiction Unit (SerT), Naples, Italy

Neurological dysfunctions are the most impactful and persistent consequences of traumatic brain injury (TBI). Indeed, previous reports suggest that an association between TBI and chronic pain syndromes, as well anxio-depressive behaviors, tends to be more common in patients with mild forms of TBI. At present, no effective treatment options are available for these symptoms. In the present study, we used a weight drop mild TBI mouse model to investigate the effect of a commercially available 10\% Cannabidiol (CBD) oil on both the sensorial and neuropsychiatric dysfunctions associated with mild TBI through behavioral and biomolecular approaches. TBI mice developed chronic pain associated with anxious and aggressive behavior, followed by a late depressive-like behavior and impaired social interaction. Such behaviors were related with specific changes in neurotransmitters release at cortical levels. CBD oral treatment restored the behavioral alterations and partially normalized the cortical biochemical changes. In conclusion, our data show some of the brain modifications probably responsible for the behavioral phenotype associated with TBI and suggest the $\mathrm{CBD}$ as a pharmacological tool to improve neurological dysfunctions caused by the trauma.

Keywords: cannabidiol, traumatic brain injury, pain, behavior, microdialysis

\section{INTRODUCTION}

The phytocannabinoid cannabidiol (CBD), the major non-psychoactive constituent of Cannabis sativa, exhibits a broad spectrum of potential therapeutic properties, including neuroprotective effects in Central Nervous System (CNS) disorders (Fernández-Ruiz et al., 2013; De Gregorio et al., 2018; Schonhofen et al., 2018). Through a multitarget mechanism, CBD shows potent anti-inflammatory and anti-oxidant properties which have been previously demonstrated in different models of neurodegenerative diseases and in acute episodes of brain damage (i.e., hypoxia-ischemia) (Hayakawa et al., 2007, 2010; Castillo et al., 2010). CBD has very low affinity for cannabinoid receptors type 1 (CB1) and type 2 (CB2), whereas different mechanisms, such as inhibition of anandamide uptake and enzymatic hydrolysis (Lastres-Becker et al., 2005), and 
decrease of adenosine reuptake (Carrier et al., 2006), are believed to be responsible for its neuroprotective effects.

Traumatic brain injury (TBI) is a complex injury with a number of symptoms accompanied by inflammatory process and cell death (Arciniegas, 2011; Liu et al., 2019). It is characterized by an initial neuroinflammation, mediated by a rapid glia cells activation, peripheral immune cells recruitment and secretion of inflammatory cytokines, followed by the late appearance of psychologically debilitating symptoms and cognitive impairments (Woodcock and Morganti-Kossmann, 2013). Despite recent advances in the knowledge of TBI pathophysiology, no adequate pharmacotherapies are currently available (Loane and Faden, 2010). It is assumed that the secondary neuropsychiatric changes that occur as a consequence of trauma are associated with plastic rearrangements at hippocampal and cortical circuitry (Schwarzbold et al., 2008). In these brain regions endocannabinoid (EC) molecules induce pro-homeostatic and neuroprotective effects, by affecting neuroplasticity in cognitive and affective processes (Vigano et al., 2009; Boccella et al., 2019). A growing body of evidence suggests that the pharmacological manipulation of EC attenuates neuroinflammation and improve the recovery of neurobehavioral function during the early weeks after TBI (Shohami et al., 2011; Mayeux et al., 2017; Schurman and Lichtman, 2017). To our knowledge, no study has evaluated the effects of CBD on the neurological dysfunctions associated with the TBI. In particular, we coupled behavioral tasks and biochemical evaluations to assess the CBD effects on long-term cognitive and emotional responses induced by trauma.

\section{MATERIALS AND METHODS}

\section{Animals}

Male C57BL/6 mice (Charles River, Italy) weighing 18-20 g were housed three per cage under controlled illumination (12 h light/dark cycle; light on 6:00 A.M.) and standard environmental conditions (ambient temperature 20$22^{\circ} \mathrm{C}$, humidity $55-60 \%$ ) for at least 1 week before the commencement of experiments. Mice chow and tap water were available ad libitum. The experimental procedures were approved by the Animal Ethics Committee of University of Campania "L. Vanvitelli," Naples. Animal care was in compliance with Italian (D.L. 116/92) and European Commission (O.J. of E.C. L358/1 18/12/86) regulations on the protection of laboratory animals. All efforts were made to reduce both animal numbers and suffering during the experiments.

\section{Mild TBI Induction}

Experimental mTBI was performed using a weight-drop device developed in our laboratory. Mice were anesthetized with intraperitoneal injection of Tribromoethanol $(250 \mathrm{mg} / \mathrm{kg})$ and placed in a prone position on a spongy support. The head was not fixed. After a midline longitudinal incision, the skull was exposed to locate the area of impact and placed under a metal tube device where the opening was positioned directly over the animal's head. The injury was induced by dropping a cylindrical metal weight $(50 \mathrm{~g})$, through a vertical metal guide tube from a height of $20 \mathrm{~cm}$. The point of impact was between the anterior coronal suture (Bregma) and posterior coronal suture (Lambda). Immediately following injury, the skin was closed with surgical wound clips and mice were placed back in their cages to allow for recovery from the anesthesia and mTBI. Sham mice were submitted to the same procedure as described for mTBI, but without release of the weight. Sham and mTBI animals did not receive analgesic drugs after surgery. No animals have been excluded from the study.

\section{Drugs}

Cannabidiol and vehicle were kindly provided by Enecta Group, Bologna (BO), Italy https://www.enecta.eu/?lang CBD was dissolved in hemp seed oil and natural tocopherols, used as vehicle. CBD (30 $\mu \mathrm{l}$, oil 10\%) was administered via gavage from day 1 to day 14 and from day 50 to day 60. Those time points represent the pathological windows in which we previously observed the main features of the mTBI, such as aggressiveness, recklessness and/or sensorial changes in the first phase, and the depressive-like behavior in a late phase (Guida et al., 2017a).

\section{Experimental Design}

Time points of evaluations were based on our previous study (Guida et al., 2017a). A total number of 80 mice were divided in four experimental groups: Sham/vehicle, mTBI/vehicle, Sham/CBD and $\mathrm{mTBI} / \mathrm{CBD}$. Behavioral tasks were performed at different time points and scheduled in order to avoid carry-over effects from prior testing experience. The number of animals for each experiment is represented in Table $\mathbf{1}$.

Following behavioral testing, mice were scarified for microdialysis experiments at 14 or 60 day after mTBI induction. The timeline of mTBI induction, treatments and behavioral and biochemical characterization is given in the Figure 1. Observers were blind to the treatments in each experiment.

\section{Tactile Allodynia}

Tactile allodynia was evaluated at a series of calibrated nylon von Frey monofilaments (Semmes-Weinstein monofilaments, 2 Biological Instruments, Italy). Mice were allowed 7, 14 and 21 days after mTBI or sham surgery by to move freely in the compartment of the enclosure positioned on the metal mesh surface. Mice were adapted to the testing environment for $30 \mathrm{~min}$ before any measurement was taken. The monofilaments, starting from the $0.008 \mathrm{~g}$ monofilament, was applied perpendicularly to the plantar surface of each hindpaw in a series of ascending forces $(0.008,0.02,0.04,0.07$, $0.16,0.40,0.60,1.0,1.4,2.0$, and $4.0 \mathrm{~g}$ ). Each stimulus was applied for approximately $1 \mathrm{~s}$ with an interstimulus interval of $5 \mathrm{~s}$. Withdrawal responses evoked by each monofilament was obtained from five consecutive trials. Data (gr) were expressed as a mean of right and left response hind paws. 
TABLE 1 | Numbers of animals used in each experiment.

\begin{tabular}{|c|c|c|c|c|c|c|}
\hline \multirow[t]{2}{*}{ Groups } & \multicolumn{6}{|c|}{ Days } \\
\hline & 0 & 7 & $13-15$ & 21 & 34 & $59-61$ \\
\hline Sham/vehicle & $N=20$ & $\begin{array}{c}N=12 \text { (Pain) } \\
N=10 \text { (Rotarod) }\end{array}$ & $\begin{array}{c}N=10 \text { (Pain) } N=10 \text { (Rotarod) } \\
N=6 \text { (Anxiety) } \\
N=10 \text { (Aggressive) } \\
N=9 \text { (Depression) }\end{array}$ & $\begin{array}{c}N=5 \text { (Pain) } \\
N=5 \text { (Rotarod) }\end{array}$ & $N=5$ (Pain) & $\begin{array}{c}N=5 \text { (Rotarod) } N=3 \\
\text { (Sociability) } N=5 \text { (Aggressive) } \\
N=12 \text { (Depression) }\end{array}$ \\
\hline Sham/CBD & $N=20$ & $\begin{array}{c}N=13 \text { (Pain) } \\
N=10 \text { (Rotarod) }\end{array}$ & $\begin{array}{c}N=10 \text { (Pain) } N=10 \text { (Rotarod) } \\
N=6 \text { (Anxiety) } \\
N=10 \text { (Aggressive) } \\
N=9 \text { (Depression) }\end{array}$ & $\begin{array}{c}N=5 \text { (Pain) } \\
N=5 \text { (Rotarod) }\end{array}$ & $N=5$ (Pain) & $\begin{array}{c}N=5 \text { (Rotarod) } N=3 \\
\text { (Sociability) } N=5 \text { (Aggressive) } \\
N=12 \text { (Depression) }\end{array}$ \\
\hline mTBl/vehicle & $N=20$ & $\begin{array}{c}N=13 \text { (Pain) } \\
N=10(\text { Rotarod })\end{array}$ & $\begin{array}{c}N=10 \text { (Pain) } N=10 \text { (Rotarod) } \\
N=6 \text { (Anxiety) } \\
N=10 \text { (Aggressive) } \\
N=9 \text { (Depression) }\end{array}$ & $\begin{array}{c}N=5 \text { (Pain) } \\
N=6 \text { (Rotarod) }\end{array}$ & $N=5$ (Pain) & $\begin{array}{c}N=5 \text { (Rotarod) } \\
N=3 \text { (Sociability) } \\
N=5 \text { (Aggressive) } \\
N=12 \text { (Depression) }\end{array}$ \\
\hline mTBl/CBD & $N=20$ & $\begin{array}{c}N=13 \text { (Pain) } \\
N=10(\text { Rotarod })\end{array}$ & $\begin{array}{c}N=11 \text { (Pain) } N=10 \text { (Rotarod) } \\
N=6 \text { (Anxiety) } \\
N=10 \text { (Aggressive) } \\
N=9 \text { (Depression) }\end{array}$ & $\begin{array}{c}N=5 \text { (Pain) } \\
N=6 \text { (Rotarod) }\end{array}$ & $N=5$ (Pain) & $\begin{array}{c}N=5 \text { (Rotarod) } N=3 \\
\text { (Sociability) } N=5 \text { (Aggressive.) } \\
N=13 \text { (Depression) }\end{array}$ \\
\hline
\end{tabular}

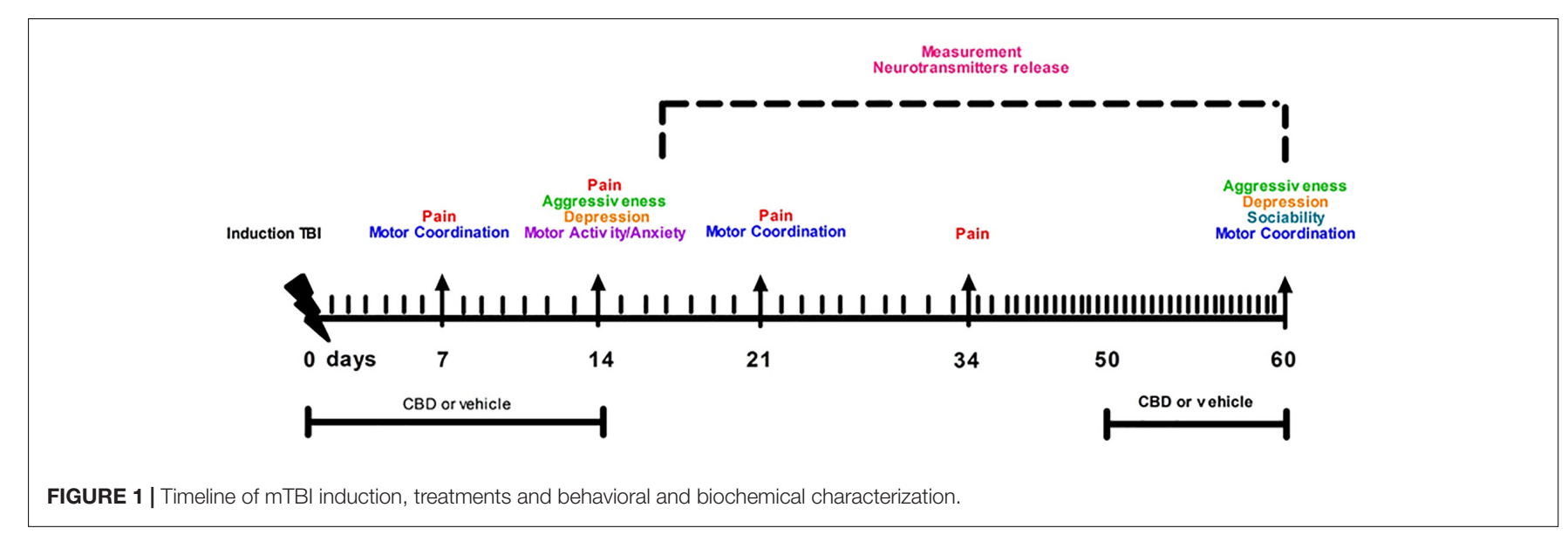

Voluntary movement, associated with the locomotion, was not counted as a withdrawal response. Tactile allodynia was defined as a significant decrease in the withdrawal threshold to the von Frey hair application. Each mouse served as its own control, the responses being measured both before and after surgical procedures.

\section{Rotarod Test}

Possible motor coordination impairment was evaluated at 7 , 21 , and 60 days after mTBI or sham surgery by Rotarod test (Ugo Basile). Mice was measured for the time (s) of equilibrium before falling on a rotary cylinder by a magnet that, activated from the fall of the mouse on the plate, allows to record the time of permanence on the cylinder. After a period of adaptation of $30 \mathrm{~s}$, the spin speed gradually increases from 5 to $40 \mathrm{rpm}$ for a maximum time of $5 \mathrm{~min}$. The animals were analyzed by two separate tests at 1-hour interval in the same day. The experiment was performed for every group of animals the day before the surgical procedure and the days before the behavioral tests in order to avoid stress. The time of permanence of the mouse on the cylinder was expressed as latency time (s).

\section{Open Field Test}

Motor activity was also evaluated by open field test in sham and mTBI mice. Briefly, each mouse was individually monitored for $5 \mathrm{~min}$ in an open arena $(1 \times \mathrm{w} \times \mathrm{h}: 25 \mathrm{~cm} \times 25 \mathrm{~cm}$ divided into 16 square grids). Parameters evaluated included: (1) number of transitions; and (2) number of rearings; and (3) time spent in the periphery or center (s).

\section{Resident-Intruder}

At 14 and 60 days after mTBI or sham surgery, mice were tested for aggressive behavior using a resident intruder test. Mice were individually housed for 1 week in Plexiglas cages to establish a home territory and to increase the aggression of the resident experimental mice. To begin, food containers were removed and an intruder mouse of the same gender was placed in a resident home cage and resident-intruder interactions were analyzed for $10 \mathrm{~min}$. The 
aggressive behavior of resident socially-isolated mice was characterized by an initial pattern of exploratory activity around the intruder, which was followed by rearing and tail rattle, accompanied in a few seconds by wrestling and/or a violent biting attack. The number of these attacks and latency to the first attack during the 10 min observation period was recorded.

\section{Three Chambers Sociability}

Test at 60 days after mTBI or sham surgery, mice were tested for social interaction using a three-chambered social interaction apparatus. A plexi-glass three-chambered box was custom-built as follows: doorways in the two dividing walls had sliding covers to control access to the outer-side chambers. The test consisted of two consecutive stages of 5 and 10 min each. During the 5-minute first stage of habituation the mouse was allowed to freely explore the three chambers of the apparatus, detecting at this stage any innate side preference. After that the mouse was gently encouraged into the central chamber and confined there briefly by closing the side chamber doors. During the following 10-minute stage sessions, a custom made stainless-steel barred cup $(6.5 \mathrm{~cm} \times 15 \mathrm{~cm})$ was placed upside down in one of the side chambers. A never before-met intruder, previously habituated, was placed into an upside-down identical cup in the other chamber. The time spent sniffing each upside-down cup, the time spent in each chamber and the number of entries into each chamber were recorded.

\section{Tail Suspension Test (TST)}

The Depression like behavior was evaluated at 14 days and 60 days after mTBI or sham surgery, mice were individually suspended by the tail on a horizontal bar $(55 \mathrm{~cm}$ from floor) using adhesive tape placed approximately $4 \mathrm{~cm}$ from the tip of the tail. The duration of immobility, recorded in seconds, was monitored during the last $4 \mathrm{~min}$ of the 6-minute test by a time recorder. Immobility time was defined as the absence of escape-oriented behavior. Mice were considered to be immobile when they did not show any body movement, hung passively and completely motionless.

\section{Microdialysis in vivo}

Microdialysis experiments were performed in awake and freely moving mice. In brief, mice were anesthetized with pentobarbital (50 mg/kg, i.p.) and stereotaxically implanted with concentric microdialysis probes into the mPFC using the coordinates: AP: $1.4-1.8 \mathrm{~mm}$, L: $0.3-05 \mathrm{~mm}$ from bregma and V: $3.0 \mathrm{~mm}$ below the dura (Paxinos and Franklin, 2004). Dialysis probes, were constructed with $25 \mathrm{G}(0.3 \mathrm{~mm}$ inner diameter, $0.5 \mathrm{~mm}$ outer diameter) stainless steel tubing (A-M Systems). Inlet and outlet cannulae (0.04 $\mathrm{mm}$ inner diameter, $0.14 \mathrm{~mm}$ outer diameter) consisted of fused silica tubing (Scientific Glass Engineering). The probe had a tubular dialysis membrane (Enka AG, Wuppertal, Germany) $1.3 \mathrm{~mm}$ in length. Following a recovery period of $24 \mathrm{~h}$, dialysis was commenced with aCSF ( $\mathrm{NaCl} 147 \mathrm{mM}, \mathrm{CaCl}_{2}$ 2.2, $\mathrm{KCl} 4 \mathrm{mM}$; pH 7.2) perfused at a rate of $1 \mu \mathrm{L} / \mathrm{min}$ by a Harvard Apparatus infusion pump. The neurotransmitters release was evaluated after chronic treatment performed with CBD or Vehicle in $\mathrm{m}$-TBI or sham animals. Data were expressed as the average of six repeated measurements (each $30 \mathrm{~min}$ ) to give a more accurate value. No appreciable differences were observed between the different six dyslisate samples collected during the single experiment. At the end of experiments, mice were anesthetized and their brains perfused fixed via the left cardiac ventricle with heparinized paraformaldehyde saline (4\%). Brains were dissected out and fixed in a $10 \%$ formaldehyde solution for 2 days and included in OCT compound. The brain was cut in $40-\mu \mathrm{m}$ thick slices and observed under a light microscope to identify

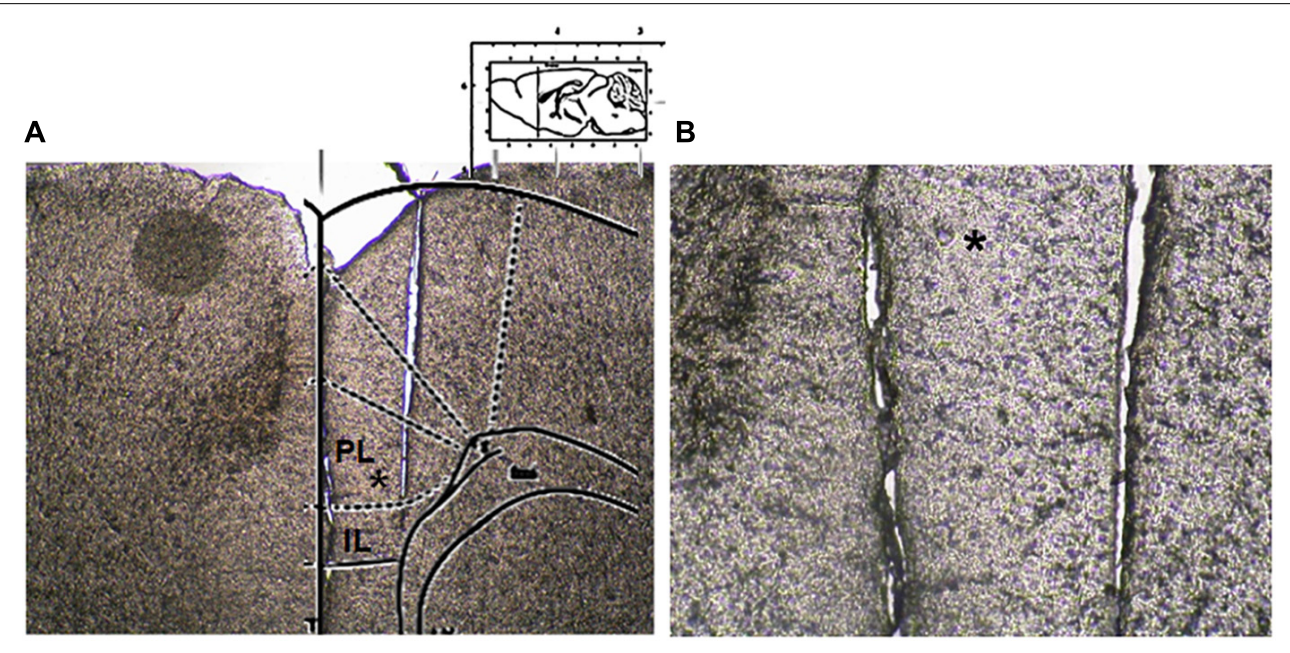

FIGURE 2 | Microdialysis probe location. (A) Shows a panoramic picture of the pre-frontal cortex, the star indicates the prelimbic area. (B) Shows a high magnification of the microdialysis probe location for amino acid collection within the pre/infra-limbic cortex. 
the probe locations (Figure 2). The concentrations of DAspartate, L-glutamate and GABA contained in the dialysate were analyzed using by HPLC coupled with fluorimetric detection method. The system comprised two Gilson pumps (model no. 303), a C-18 reverse-phase column, and a Gilson fluorimetric detector (model no. 121). Dialysates were pre-column derivatized with $o$-phthaldialdehyde$N$-acetylcysteine (OPA-NAC) $(10 \mu l$ dialysate $+5 \mu \mathrm{l}$ OPA-NAC + $10 \mu$ l borate buffer $10 \%)$. The mobile phase consisted of two components: (A) $0.2 \mathrm{M} \mathrm{Na} \mathrm{HPO}_{4}, 0.2$ $\mathrm{M}$ citric acid and 20\% methanol and (B) 90\% acetonitrile. Gradient composition was determined using an Apple microcomputer installed with Gilson gradient management software. Mobile phase flow rate was maintained at $1.2 \mathrm{ml} / \mathrm{min}$. Data were collected using a Dell Corporation PC system 310 interfaced to the detector via a Drew data-collection unit. Data were expressed as mean \pm SEM of six samples for each mouse.

\section{Statistical Analysis}

Data were represented as mean \pm SEM. Behavioral data were analyzed by using one-way ANOVA, followed by Bonferroni's multiple comparison. Newman-Keuls post hoc test was used as post hoc test in microdialysis analysis. $P$ values $<0.05$ were considered statistically significant. Statistical analysis was carried out using Prism/Graphpad (GraphPad Software, Inc.)) software. Numbers of animals used in each experiment is given in Table 1.

\section{RESULTS}

\section{CBD Effects on Allodynia in mTBI Mice}

A significant decrease of TWT was observed in vehicletreated mTBI mice at 7,14 , and 21 days after trauma induction $[0.14 \mathrm{~g} \pm 0.025, F(3,47)=11.06, P<0.0001$; $0.11 \mathrm{~g} \pm 0.04, F(3,37)=12.40, P<0.0001 ; 0.11 \mathrm{~g} \pm 0.04$, $F(3,16)=8.833, P=0.0011$, at 7,14 , and 21 days, respectively] compared to the sham group $(0.63 \mathrm{~g} \pm 0.12$, $0.61 \mathrm{~g} \pm 0.09,0.62 \mathrm{~g} \pm 0.1$, at 7, 14, and 21 days, respectively) (Figure 3A). Moreover, a physiological re-establishment of normal pain response was observed 34 days after trauma induction [Sham/vehicle $0.62 \mathrm{~g} \pm 0.06$; Sham/CBD $0.65 \mathrm{~g} \pm 0.1$; $\mathrm{mTBI} /$ vehicle $0.64 \mathrm{~g} \pm 0.22 ; \mathrm{mTBI} / \mathrm{CBD} 0.62 \mathrm{~g} \pm 0.07$ $F(3,16)=0.01345, P=0.9978$ ] (Figure 3A). No difference in pain threshold was observed between right and left paw (see Supplementary Table S1). Oral CBD treatment significantly reduced the tactile allodynia in mTBI mice at 14 and 21 days (0.28 $\mathrm{g} \pm 0.04 ; 0.41 \mathrm{~g} \pm 0.04 ; 0.46 \pm 0.02$, at 7, 14, and 21 days, respectively) as compared with vehicle $(0.14 \mathrm{~g} \pm 0.025$; $0.11 \mathrm{~g} \pm 0.04 ; 0.11 \mathrm{~g} \pm 0.04$, at 7, 14, and 21 days, respectively) (Figure 3A). The CBD administration in sham mice did not change the pain response $(0.71 \mathrm{~g} \pm 0.17 ; 0.51 \mathrm{~g} \pm 0.07$; $0.41 \mathrm{~g} \pm 0.09 ; 0.65 \pm 0.1$ at 7,14 and 21 , and 34 days, respectively) compared to sham/vehicle mice $(0.63 \mathrm{~g} \pm 0.12$; $0.61 \mathrm{~g} \pm 0.09 ; 0.62 \mathrm{~g} \pm 0.1 ; 062 \pm 0.06$, at $7,14,21$, and 34 days, respectively).

\section{CBD Effects on Motor Coordination and Anxiety in mTBI Mice}

In the rotarod test, no difference in riding time was observed between any of the treatment groups (Figure 3B), indicating no impairments in motor coordination. In the open field test, used to assay general locomotor activity levels, but also anxiety, one-way ANOVA, followed by Bonferroni post hoc test, revealed no significant changes in the time spent in the center [sham/vehicle $73.33 \mathrm{~s} \pm 15.63$; sham/CBD 56.83 $\mathrm{s} \pm 5.31 ; \mathrm{mTBI} /$ vehicle $53.80 \mathrm{~s} \pm 19.51 ; \mathrm{mTBI} / \mathrm{CBD}$ $46.67 \mathrm{~s} \pm 10.05, F(3,19)=0.7663, P=0.5269)$ or in the periphery [sham/vehicle $241.7 \mathrm{~s} \pm 9.86$; sham/CBD $243.2 \mathrm{~s} \pm 5.31 ; \mathrm{mTBI} /$ vehicle $268.8 \mathrm{~s} \pm 12.89 ; \mathrm{mTBI} / \mathrm{CBD}$ $263.3 \mathrm{~s} \pm 11.12, F(3,19)=1.896, P=0.1646]$ or for the number of transitions [sham/vehicle $204.5 \pm 17.50$; sham/CBD $239.8 \pm 10.41 ; \mathrm{mTBI} /$ vehicle $226.8 \pm 13.62$; $\mathrm{mTBI} / \mathrm{CBD} 238.8 \pm 14.06, F(3,20)=1.354, P=0.2854]$ after trauma or any treatment (Figures 3C,E,F). However, $\mathrm{mTBI} /$ vehicle $[52.5 \pm 2.38 ; F(3,20)=24.00, P<0.0001]$ mice showed an increase in the number of rearing as compared to sham/vehicle $(12.50 \pm 3.17)$ and this effect was significantly reduced by CBD treatment $(33.33 \pm 4.10)$. CBD did not change the number of rearing in sham animals $(25.33 \pm 3.77)$ (Figure 3D).

\section{CBD Effects on Aggressive Behavior in mTBI Mice}

No difference in the latency to the first attack in all groups of mice at 14 and 60 days after brain injury was observed [sham/vehicle $470.3 \mathrm{~s} \pm$ 38.56; sham/CBD $424.6 \mathrm{~s} \pm 71.80$; $\mathrm{mTBI} /$ vehicle $463.4 \mathrm{~s} \pm 37.26 ; \mathrm{mTBI} / \mathrm{CBD} 424.5 \mathrm{~s} \pm 34.10$, $F(3,36)=0.2630, P=0.8516$; sham/vehicle $227.4 \mathrm{~s} \pm 48.53$; sham/CBD $200.4 \mathrm{~s} \pm 53.56 ; \mathrm{mTBI} /$ vehicle $186.4 \mathrm{~s} \pm 53.51$ $\mathrm{mTBI} / \mathrm{CBD} 226.0 \mathrm{~s} \pm 45.33, F(3,16)=0.1588, P=0.9225]$ (Figures 4A,C). However, 14 days after the trauma, mTBI mice showed an increased number of attacks $[20.20 \pm 2.99$, $F(3,36)=5.353, P=0.0037]$, as compared to the controls $(10.60 \pm 1.36)$ (Figure 4B). CBD treatment significantly reduced this effect $(9.9 \pm 1.84)$ as compared with vehicle $(20.20 \pm 2.99)$. At 60 days after trauma, no significant change was observed in the number of attacks [sham/vehicle $0.6 \pm 0.4$; sham/CBD $0.8 \pm 0.37 ; \mathrm{mTBI} /$ vehicle $0.8 \pm 0.37 ; \mathrm{mTBI} / \mathrm{CBD} 0.4 \pm 0.24$, $F(3,16)=0.2933, P=0.8296]$. Sham mice treated with CBD did not show any change in the latency to the first attack or number of attacks compared to sham/vehicle mice (Figures 4C,D).

\section{CBD Effects on Depressive-Like Behavior in mTBI Mice}

mTBI mice showed an increased immobility time, measured as the lack of escape-oriented activity (169.4 s \pm 5.93) compared to the sham mice (132.4 s \pm 4.15$) 60$ days post trauma (Figure 5A). CBD treatment significantly reduced the immobility in mTBI condition (125.1 $\mathrm{s} \pm 8.95)$ compared to the vehicle (169.4 s \pm 5.93) (Figure 5A). Sham mice treated with CBD did not show any change in the duration of immobility compared to vehicle-treated 


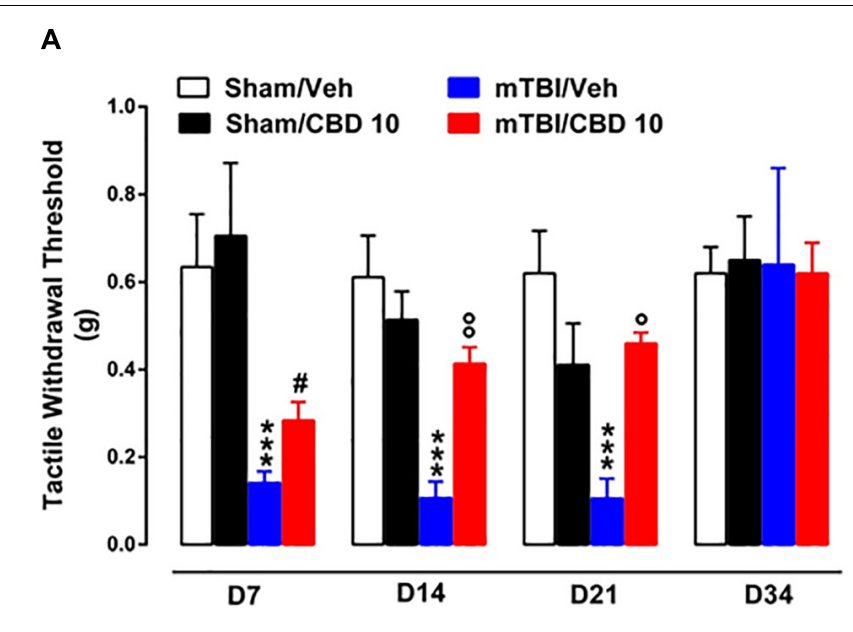

C

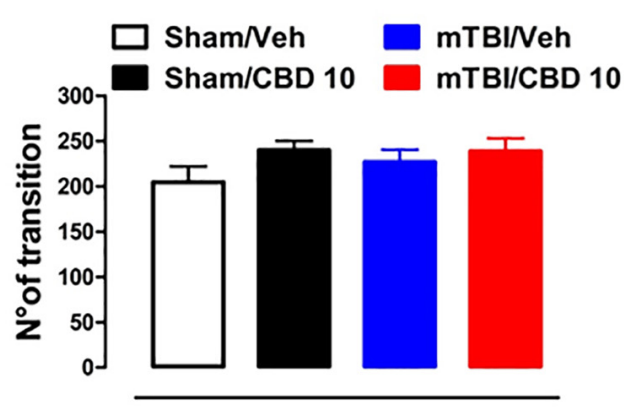

E

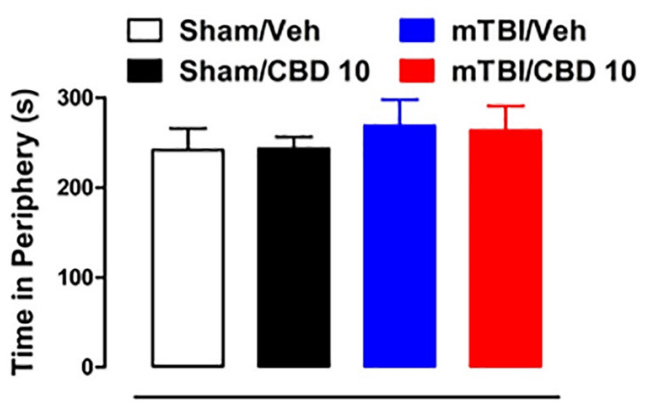

B
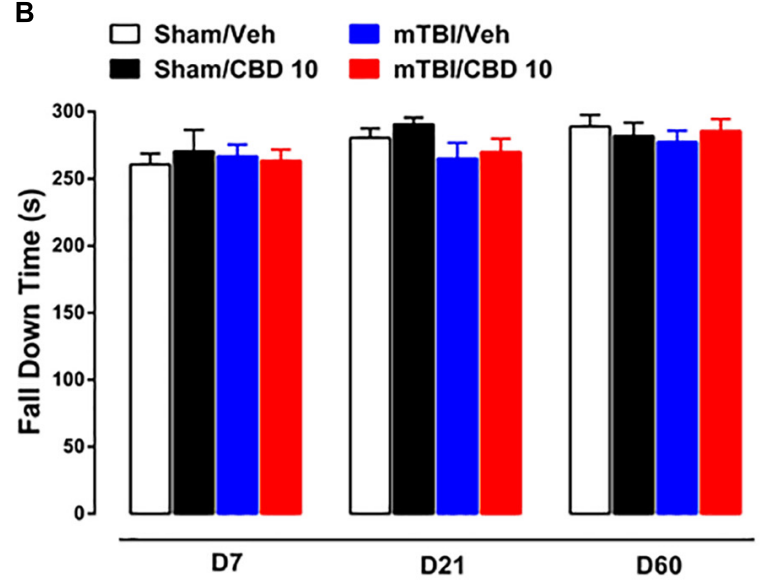

D
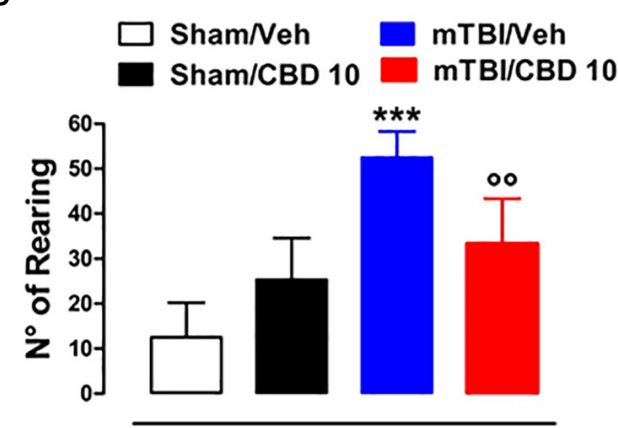

$\mathbf{F}$

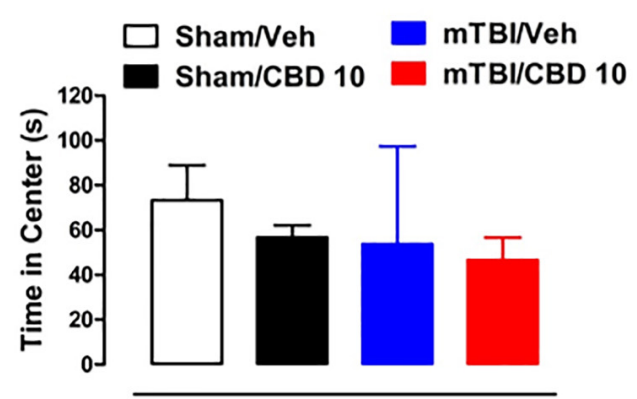

FIGURE 3 | Effect of CBD on behavioral evaluations in sham and mTBI mice. (A) Shows Tactile withdrawal thresholds (TWT) measured through Von Frey monofilaments, (B) shows the latency to fall in the rotarod test, (C-F) show the number of transitions, number of rearing, the time spent in the periphery or in the center, in the open field test, respectively. Data are represented as mean \pm SEM of $10-11$ mice per group. ${ }^{*},{ }^{\#}$ and ${ }^{\circ}$ indicate significant differences compared to sham/vehicle, sham/CBD 10 or TBI/vehicle, respectively. $P<0.05$ was considered statistically significant. One-way ANOVA, followed by Bonferroni's Multiple Comparison post hoc tests.

mice $[110.4 \mathrm{~s} \pm 10.53, F(3,45)=13.64, P<0.0001]$ (Figure 5A). At 14 days mTBI mice did not shown any change in the immobility time as compared with sham animals (Supplementary Figure S1).

\section{CBD Effects on Social Behavior in mTBI Mice}

Analysis of the social preference revealed an impairment of social interaction which occurred 60 days post trauma.
In the three chambers sociability test, no difference in the time spent in each chamber or in the number of transitions was observed in mTBI and Sham mice treated with vehicle or CBD (Supplementary Table S2). However, mTBI mice had reduced sociability level, spending a higher time in interacting with the object during the recorded time [27.33 s $\pm 4.1 ; F(3,8)=11.40, P<0.0029]$, compared to sham animals (4.67 $\mathrm{s} \pm 0.88$ ) (Figure 5B, session I). This effect was significantly improved in mTBI CBD-treated animals (5.0 s \pm 1.0$)$. Moreover, mTBI mice [interaction 


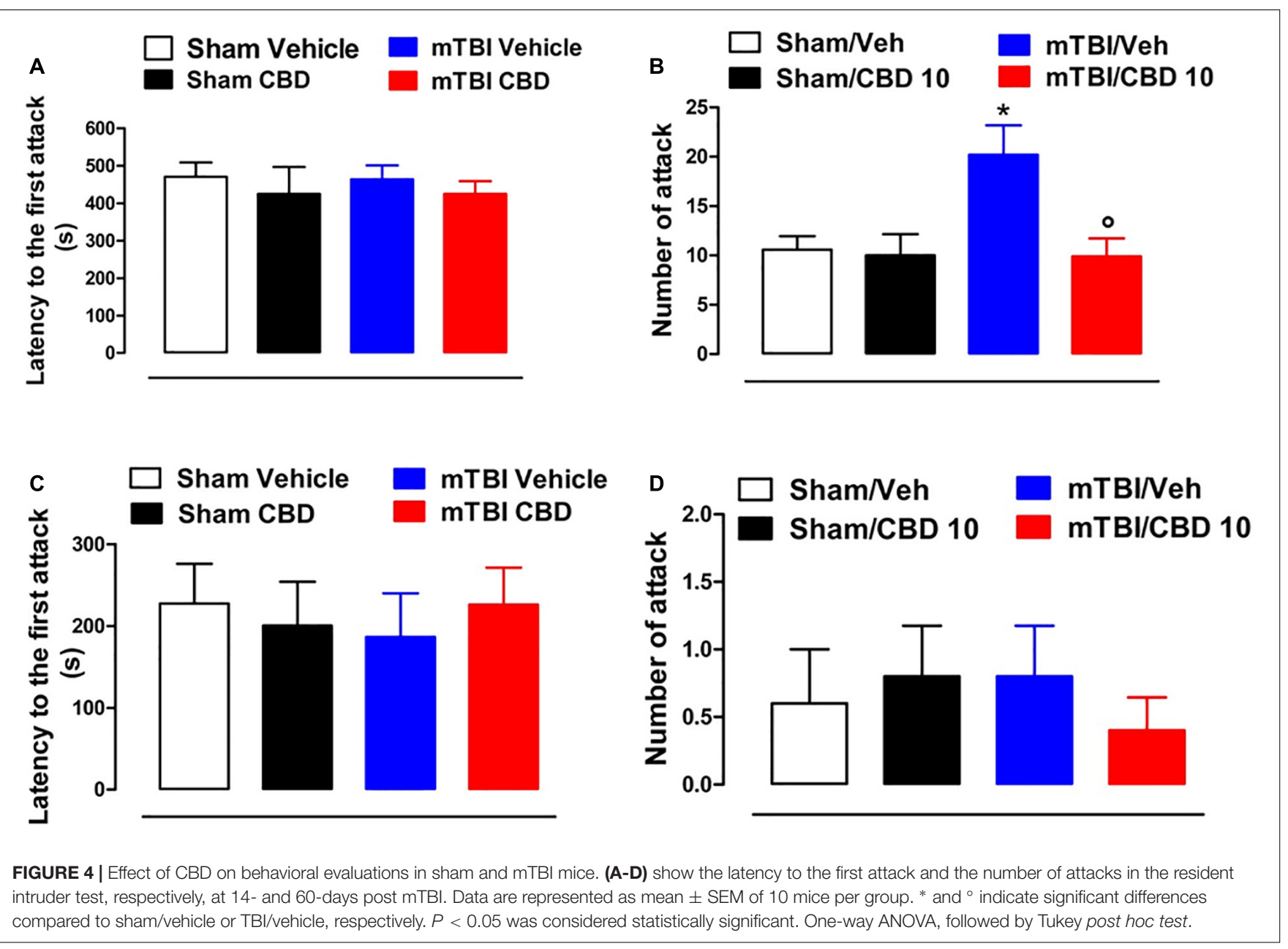

with mouse II: $24.0 \mathrm{~s} \pm 11.55 F(3,8)=1.308, P=0.3373]$ did not show significantly altered preference for social novelty compared with control mice (interaction with mouse II: $40.67 \mathrm{~s} \pm 11.05$ ) (Figure $5 \mathrm{C}$, session II). The CBD treatment did not induce any change in sociability, in the time spent in the two chambers or in the number of transitions between the chambers compared to vehicle in sham or mTBI animals (Sham/CBD and mTBI/CBD: interaction with mouse II: $39.67 \mathrm{~s} \pm 7.86$ and $48.67 \pm 2.91$ ) (Figures 5A,B).

\section{CBD Effects on Neurotransmitters Release mTBI Mice}

In vivo microdialysis was used to assess the amino acids contents in the m-PFC of mTBI mice. HPLC analysis revealed a notable increase of extracellular glutamate (Glu) and D-Aspartate (D-Asp) levels in the mPFC of 14 days mTBI animals [Glu: $32.05 \mathrm{pmol} / \mu \mathrm{l} \pm 1.33$ $F(3,12)=123.1, P<0.0001 ;$ D-Asp: $2.29 \mathrm{pmol} / \mu \mathrm{l} \pm 0.38$; $F(3,8)=7.922, P=0.0088]$, as compared with controls (Glu: $7.12 \mathrm{pmol} / \mu \mathrm{l} \pm$ 0.26; D-Asp: $0.93 \mathrm{pmol} / \mu \mathrm{l} \pm 0.42$ ). Remarkably, CBD treatment normalized both Glu and D-Asp levels (Glu: $9.43 \mathrm{pmol} / \mu \mathrm{l} \pm 0.55$; D-Asp: $0.28 \mathrm{pmol} / \mu \mathrm{l} \pm 0.06$ )
(Figures 6A,B). On the contrary, GABA levels were decreased by $\mathrm{TBI}$, and $\mathrm{CBD}$ significantly reverted this effect (sham/vehicle $3.25 \mathrm{pmol} / \mu \mathrm{l} \pm 0.6$; sham $/ \mathrm{CBD}$ $2.62 \mathrm{pmol} / \mu \mathrm{l} \pm 0.31 ; \mathrm{mTBI} /$ vehicle $0.191 \mathrm{pmol} / \mu \mathrm{l} \pm 0.01 ;$ $\mathrm{mTBI} / \mathrm{CBD} 1.38 \mathrm{pmol} / \mu \mathrm{l} \pm 0.13, \quad F(3,12)=15.74$ $P=0.0002$ ) (Figure 6C). At 60 days post mTBI, while GABA and D-Asp dialysate were not changed [GABA: sham/vehicle $2.21 \mathrm{pmol} / \mu \mathrm{l} \pm 0.01$; sham/CBD $3.65 \mathrm{pmol} / \mu \mathrm{l} \pm 1.08 ; \mathrm{mTBI} /$ vehicle $1.51 \mathrm{pmol} / \mu \mathrm{l} \pm 0.36$; $\mathrm{mTBI} / \mathrm{CBD} 2.11 \mathrm{pmol} / \mu \mathrm{l} \pm 0.36, F(3,7)=2.025 P=0.1990$; $\mathrm{D}$-Asp sham/vehicle $1.08 \mathrm{pmol} / \mu \mathrm{l} \pm 0.53$; sham/CBD $0.61 \mathrm{pmol} / \mu \mathrm{l} \pm 0.18 ; \mathrm{mTBI} /$ vehicle $0.47 \mathrm{pmol} / \mu \mathrm{l} \pm 0.10$; $\mathrm{mTBI} / \mathrm{CBD} 0.29 \mathrm{pmol} / \mu \mathrm{l} \pm 0.06, F(3,7)=2.176 P=0.1789]$ (Figures 6D,F), Glu levels were still high, but CBD did not revert this effect [Glu: sham/vehicle $10.81 \mathrm{pmol} / \mu \mathrm{l} \pm 5.33 ; \mathrm{mTBI} /$ vehicle $47.29 \mathrm{pmol} / \mu \mathrm{l} \pm 11.14 ; \mathrm{mTBI} / \mathrm{CBD} 73.62 \mathrm{pmol} / \mu \mathrm{l} \pm 4.80$, $F(3,5)=15.26 P=0.0060$ ] (Figure 6E). Finally, we found that CBD increased per sè Glu levels in the $\mathrm{mPFC}$ of sham mice at both 14- and 60-days post trauma (sham/CBD: $17.12 \mathrm{pmol} / \mu \mathrm{l} \pm 1.40 ; 47.02 \mathrm{pmol} / \mu \mathrm{l} \pm 6.09,14$ and 60 days, respectively), as compared with vehicle (sham/Vehicle: $7.12 \mathrm{pmol} / \mu \mathrm{l} \pm 0.26 ; 10.81 \mathrm{pmol} / \mu \mathrm{l} \pm 5.33,14$ and 60 days, respectively) (Figures 6B,E). 


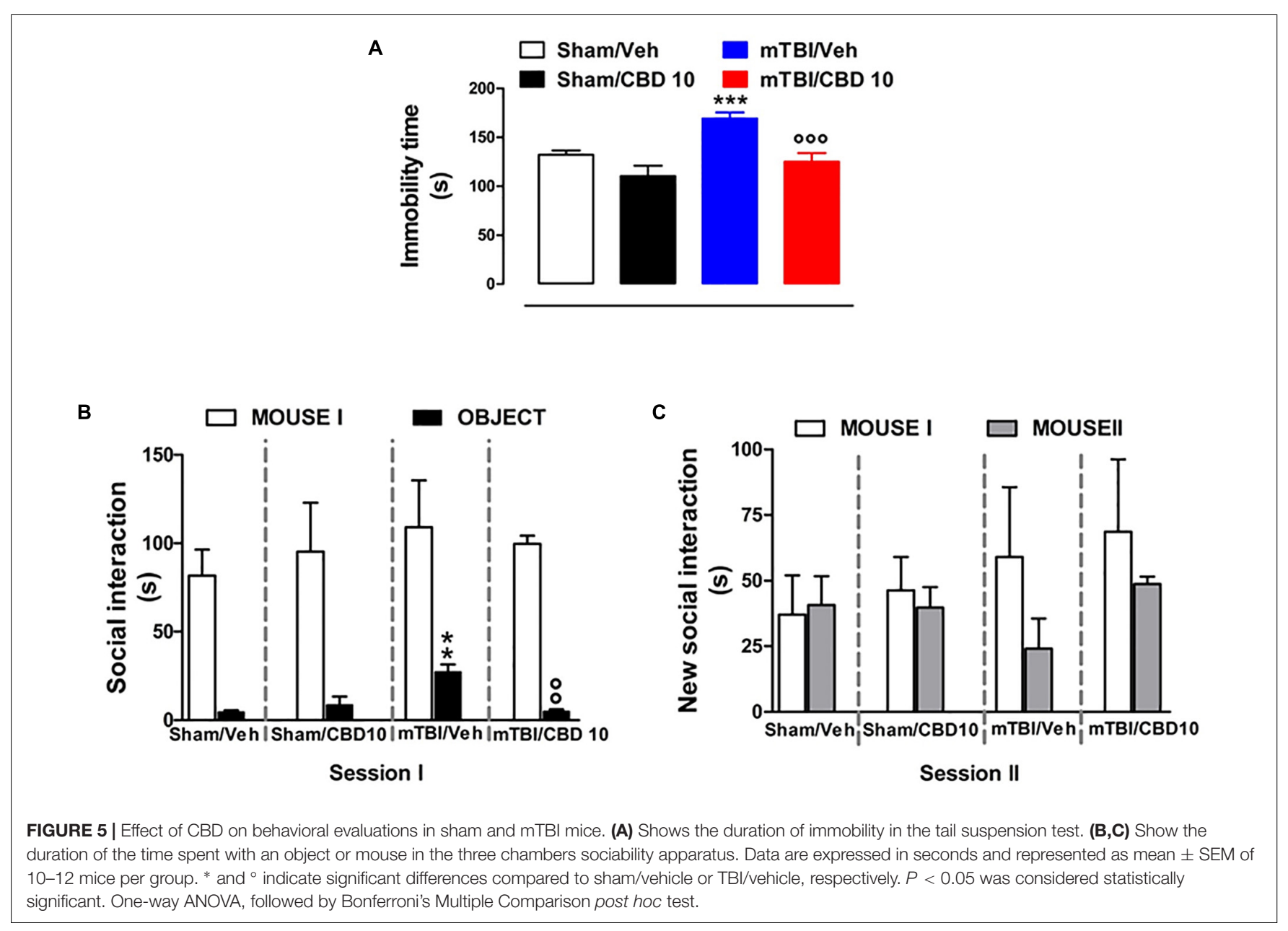

\section{DISCUSSION}

Cognitive and emotional dysfunctions are the most impactful and persistent consequences of TBI. Indeed, motor and sensory deficits and psychiatric disorders may endure for weeks, as a consequence of the traumatic damage to the underlying brain structures. We previously showed that mTBI induced late (up to 60 days) neurological dysfunctions in mice and identified electrophysiological changes at the cortical level possibly associated with symptomatology (Guida et al., 2017a). In the present study, we demonstrated that the repeated treatment with commercially available $10 \%$ CBD oil exerts beneficial effects on the behavioral dysfunctions associated with TBI. Moreover, at the dose tested, $\mathrm{CBD}$ does not change the normal attitude, in term of locomotion, nociception or emotional behavior, in not injured animals.

As previously shown (Guida et al., 2017a), 2 weeks-mTBI mice displayed abnormal pain response after innocuous stimuli to the paw (mechanical allodynia), probably due to the overall inflammatory condition (Feliciano et al., 2014). The daily treatment with CBD significantly reduced pain behavior, which, in fact, spontaneously disappeared in 30 days. Though brain trauma did not affect the motor coordination or the exploratory activity, we found an increased rearing activity in mTBI mice, which was counteracted by CBD treatment. The significance of rearing movements seems to be strongly related to the specific surrounding environment. Rearing may reflect attentive processes underlying the assembling of information in novel situations (Aspide et al., 1998), however, in some circumstances, it may simply represent an escape motivation (Lever et al., 2006). It is possible that the rearing activity in our model may reflect a kind of recklessness-like behavior, as previously reported in TBI mice (Guida et al., 2017a) and humans (DSM V). mTBI mice presented a typical phenotype, characterized by an aggressive behavior followed by a depressive-like behavior. Indeed, the aggressiveness of mTBI animals, revealed by an increased number of attacks on intruder mouse, was followed by a depressive-like behavior, manifested as enhanced immobility in the tail suspension test (14 and 60 days after trauma, respectively). The impaired social activity was also observed in the three-chamber sociability task, suggesting a general illness, often reported in patients with TBI. CBD significantly prevented all these effects. Interestingly, mTBI mice showed a reduced interest for social novelty, compared with controls. In fact, even if was not significant, we found that the time spent with the novel mouse (stranger) was reduced 


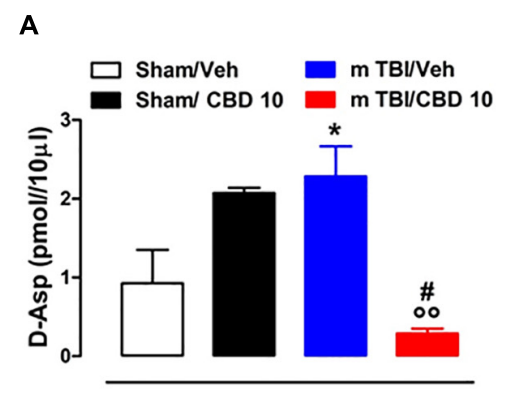

D

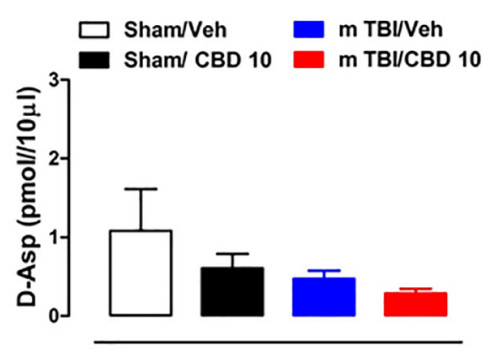

B

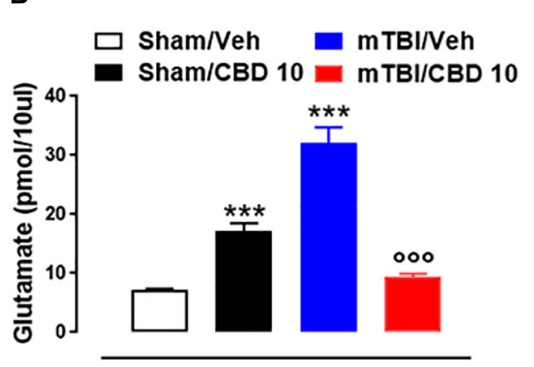

E

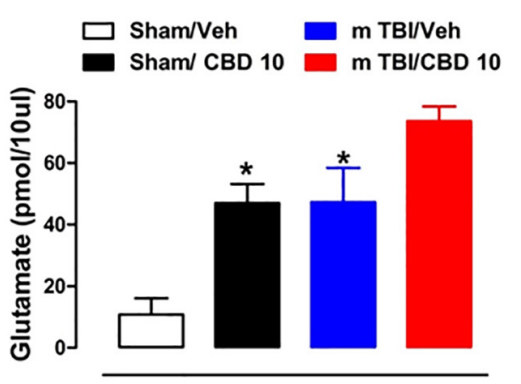

C

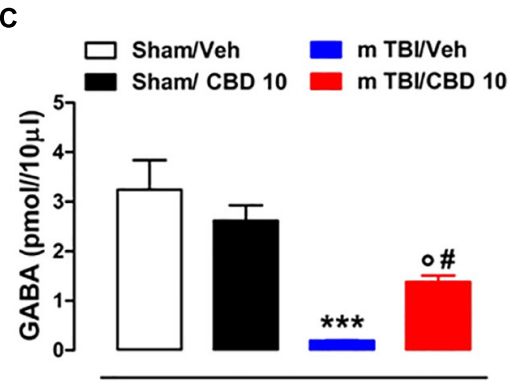

$\mathbf{F}$

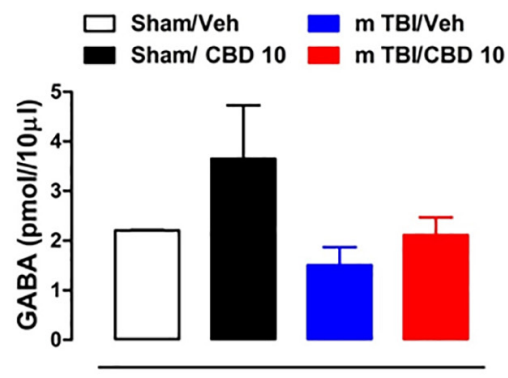

FIGURE 6 | Effect of CBD on the release of glutamate (B,E), GABA (C,F) and D-Aspartate (A,D) in sham or mTBI mice at 14 and 60 days after trauma. The values of extracellular amino acids in the mPFC were expressed as pmol in $10 \mu \mathrm{l}$ of perfusate. Each point represents the mean \pm SEM of 3-4 animals per group. ${ }^{*}$, \# and ${ }^{\circ}$ indicate significant differences compared to sham/vehicle, sham/CBD 10 or TBI/vehicle, respectively. $P<0.05$ was considered statistically significant. One- Way ANOVA, post hoc test Newman-Keuls Multiple Comparison.

after trauma, indicating an impaired recognition memory. A positive trend to the increase was given by CBD treatment. TBI strongly affects the cortical neuronal plasticity. Indeed, we have previously shown that the altered behaviors following mTBI correlated with the biphasic firing activity of the pyramidal neurons in the $\mathrm{mPFC}$, considered a key area regulating chronic pain (Giordano et al., 2011; Luongo et al., 2013) and negative affective states, such as anxiety and depression (Vialou et al., 2014; Apps and Strata, 2015; Guida et al., 2015). Remarkably, microdialysis/HPLC analysis revealed that mTBI (14 days) induced an increase of extracellular glutamate levels in the mPFC, which strengthens, the concept that plastic changes and novel neural remodeling may occur after trauma. Conversely, GABA levels were decreased, possibly as a counterbalance of the glutamate-mediated excitation. Remarkable, CBD normalized both GABA and glutamate levels. These latter data are in line with previous reports showing the protective effects of cannabinoids on the excitoxicity and inflammation correlated with glutamatergic system dysregulation in diverse neurodegenerative diseases (Guida et al., 2015, 2017b; Palazzo et al., 2015). In particular, the neuroprotective and antioxidant properties of CBD have been shown in high glutamate inducedtoxicity in rat cortical neurons (Hampson et al., 1998). Our data also indicated that the extracellular levels of D-aspartic acid (D-Asp), endogenous NMDA receptor agonist, involved in pain and synaptic plasticity (Guida et al., 2015; D'Aniello et al., 2017) enhanced in mTBI mice. This effect was decreased in CBDtreated mTBI mice. Therefore, collectively these findings indicate that mTBI may be responsible for hyper-functional glutamate/Daspartate signaling at the supraspinal level and, possibly, of the trauma-associated negative state (aggressive phenotype), at least at this time point. Indeed, while CBD reduced the depression and the impaired sociability, it was not able to change glutamate levels that were still high 60 days after trauma. This suggests the involvement of other brain areas, including the hippocampus, and/or other neurotransmissions (i.e., serotoninergic) in the altered neuropsychiatric behavioral profile of mTBI mice. Moreover, we demonstrated that CBD treatment also increased glutamate in sham mice, at both 14 and 60 days. Indeed, although it does not alter behavior in selected tasks, we cannot exclude that $\mathrm{CBD}$ may play a physiological role in other neuropsychological functions regulated by cortical processing, such as cognition, memory and reward.

\section{CONCLUSION}

In conclusion, our data demonstrate that mTBI causes late sensorial affective/cognitive deficiencies linked to altered neurotransmitter release at cortical level. Moreover, we showed that chronic CBD treatment reduces behavioral dysfunctions by restoring at least in part cortical biochemical processes. Taken together, our results suggest that $\mathrm{CBD}$ could represent a novel approach for the management of neuropsychiatric disorders associated with TBI. 


\section{AUTHOR CONTRIBUTIONS}

$\mathrm{CB}$, LL, and $\mathrm{RR}$ conceived and designed the experiments. $\mathrm{CB}, \mathrm{MI}, \mathrm{SB}, \mathrm{FR}, \mathrm{RI}$, and RM performed the experiments. GP, LS, SP, RR, LL, and IM analyzed the data and contributed to materials and analysis tools. $\mathrm{CB}, \mathrm{FG}$, and $\mathrm{SM}$ wrote the manuscript.

\section{ACKNOWLEDGMENTS}

We thank Enecta Group for providing Cannabidiol. We also thank the Department of Experimental Medicine of Universisty of Campania for publication fees.

\section{REFERENCES}

Apps, R., and Strata, P. (2015). Neuronal circuits for fear and anxiety-the missing link. Nat. Rev. Neurosci. 16:642. doi: 10.1038/nrn4028

Arciniegas, D. B. (2011). Clinical electrophysiologic assessments and mild traumatic brain injury: state-of-the-science and implications for clinical practice. Int. J. Psychol. 82, 41-52. doi: 10.1016/j.ijpsycho.2011.03.004

Aspide, R., Carnevale, U. A. G., Sergeant, J. A., and Sadile, A. G. (1998). Nonselective attention and nitric oxide in putative animal models of attentiondeficit hyperactivity disorder. Behav. Brain Res. 95, 123-133. doi: 10.1016/ S0166-4328(97)00217-9

Boccella, S., Cristiano, C., Romano, R., Iannotta, M., Belardo, C., Farina, A., et al. (2019). Ultra-micronized palmitoylethanolamide rescues the cognitive decline-associated loss of neural plasticity in the neuropathic mouse entorhinal cortex-dentate gyrus pathway. Neurobiol. Dis. 121, 106-119. doi: 10.1016/j.nbd. 2018.09.023

Carrier, E. J., Auchampach, J. A., and Hillard, C. J. (2006). Inhibition of an equilibrative nucleoside transporter by cannabidiol: a mechanism of cannabinoid immunosuppression. Proc. Natl. Acad. Sci. U.S.A. 103, 7895-7900. doi: $10.1073 /$ pnas.0511232103

Castillo, A., Tolón, M., Fernández-Ruiz, J., Romero, J., and MartinezOrgado, J. (2010). The neuroprotective effect of cannabidiol in an in vitro model of newborn hypoxic-ischemic brain damage in mice is mediated by CB2 and adenosine receptors. Neurobiol. Dis. 37, 434-440. doi: $10.1016 /$ j.nbd.2009.10.023

D’Aniello, A., Luongo, L., Romano, R., Iannotta, M., Marabese, I., Boccella, S., et al. (2017). d-Aspartic acid ameliorates painful and neuropsychiatric changes and reduces beta-amyloid abeta1-42 peptide in a long lasting model of neuropathic pain. Neurosci. Lett. 651, 151-158. doi: 10.1016/j.neulet.2017.04.041

De Gregorio, D., McLaughlin, R. J., Posa, L., Ochoa-Sanchez, R., Enns, J., LopezCanul, M., et al. (2018). Cannabidiol modulates serotonergic transmission and prevents allodynia and anxiety-like behavior in a model of neuropathic pain. Pain 160, 136-150. doi: 10.1097/j.pain.0000000000001386

Feliciano, D. P., Sahbaie, P., Shi, X., Klukinov, M., Clark, J. D., and Yeomans, D. C. (2014). Nociceptive sensitization and BDNF up-regulation in a rat model of traumatic brain injury. Neurosci. Lett. 583, 55-59. doi: 10.1016/j.neulet.2014.09.030

Fernández-Ruiz, J., Sagredo, O., Pazos, M. R., García, C., Pertwee, R., Mechoulam, R., et al. (2013). Cannabidiol for neurodegenerative disorders: important new clinical applications for this phytocannabinoid? Br. J. Clin. Pharmacol. 75, 323-333. doi: 10.1111/j.1365-2125.2012.04341.x

Giordano, C., Cristino, L., Luongo, L., Siniscalco, D., Petrosino, S., Piscitelli, F., et al. (2011). TRPV1-Dependent and -independent alterations in the limbic cortex of neuropathic mice: impact on glial caspases and pain perception. Cereb. Cortex 22, 2495-2518. doi: 10.1093/cercor/bhr328

Guida, F., Boccella, S., Iannotta, M., De Gregorio, D., Giordano, C., Belardo, C., et al. (2017a). Palmitoylethanolamide reduces neuropsychiatric behaviors by restoring cortical electrophysiological activity in a mouse model of mild traumatic brain injury. Front. Pharmacol. 8:95. doi: 10.3389/fphar.2017.00095

\section{SUPPLEMENTARY MATERIAL}

The Supplementary Material for this article can be found online at: https://www.frontiersin.org/articles/10.3389/fphar. 2019.00352/full\#supplementary-material

FIGURE S1 | Effect of CBD on depressive-like behavior in sham and mTBI mice. The duration of immobility is measured in the tail suspension test at 14 days after mTBI induction.

TABLE S1 | Effect of CBD on pain behavior in sham and mTBI mice. Left and right paw tactile withdrawal thresholds (TWT) are measured through Von Frey monofilaments at 7, 14, 21, and 34 days after mTBI induction.

TABLE S2 | Effect of CBD on social behavior in sham and mTBI mice. The time spent in each chamber $\mathbf{( A )}$ or in the number of transitions $\mathbf{( B )}$ in the three chambers sociability apparatus.

Guida, F., Palazzo, E., Luongo, L., Marabese, I., de Novellis, V., Maione, S., et al. (2017b). Supraspinal metabotropic glutamate receptors: an endogenous substrate for alleviating chronic pain and related affective disorders. $m G L U$ Receptors 31, 15-31.

Guida, F., Luongo, L., Marmo, F., Romano, R., Iannotta, M., Napolitano, F., et al. (2015). Palmitoylethanolamide reduces pain-related behaviors and restores glutamatergic synapses homeostasis in the medial prefrontal cortex of neuropathic mice. Mol. Brain 8:47. doi: 10.1186/s13041-015-0139-5

Hampson, A., Grimaldi, M., Axelrod, J., and Wink, D. (1998). Cannabidiol and () $\Delta$-tetrahydrocannabinol are neuroprotective antioxidants. Proc. Natl. Acad. Sci. U.S.A. 95, 8268-8273. doi: 10.1073/pnas.95.14.8268

Hayakawa, K., Mishima, K., and Fujiwara, M. (2010). Therapeutic potential of nonpsychotropic cannabidiol in ischemic stroke. Pharmaceuticals 3, 2197-2212. doi: 10.3390/ph3072197

Hayakawa, K., Mishima, K., Nozako, M., Hazekawa, M., Irie, K., Fujioka, M., et al. (2007). Delayed treatment with cannabidiol has a cerebroprotective action via a cannabinoid receptor-independent myeloperoxidase-inhibiting mechanism. J. Neurochem. 102, 1488-1496. doi: 10.1111/j.1471-4159.2007.04565.x

Lastres-Becker, I., Molina-Holgado, F., Ramos, J. A., Mechoulam, R., and Fernández-Ruiz, J. (2005). Cannabinoids provide neuroprotection against 6hydroxydopamine toxicity in vivo and in vitro: relevance to Parkinson's disease. Neurobiol. Dis. 19, 96-107. doi: 10.1016/j.nbd.2004.11.009

Lever, C., Burton, S., and O’Keefe, J. (2006). Rearing on hind legs, environmental novelty, and the hippocampal formation. Rev. Neurosci. 17, 111-134. doi: 10.1515/revneuro.2006.17.1-2.111

Liu, J., Xiong, X., and Sui, Y. (2019). Isoliquiritigenin attenuates neuroinflammation in traumatic brain injury in young rats. Neuroimmunomodulation 15, 1-8. doi: 10.1159/000495467

Loane, D. J., and Faden, A. I. (2010). Neuroprotection for traumatic brain injury: translational challenges and emerging therapeutic strategies. Trends Pharmacol. Sci. 31, 596-604. doi: 10.1016/j.tips.2010.09.005

Luongo, L., de Novellis, V., Gatta, L., Palazzo, E., Vita, D., Guida, F., et al. (2013). Role of metabotropic glutamate receptor 1 in the basolateral amygdaladriven prefrontal cortical deactivation in inflammatory pain in the rat. Neuropharmacology 66, 317-329. doi: 10.1016/j.neuropharm.2012.05.047

Mayeux, J., Katz, P., Edwards, S., Middleton, J. W., and Molina, P. E. (2017). Inhibition of endocannabinoid degradation improves outcomes from mild traumatic brain injury: a mechanistic role for synaptic hyperexcitability. J. Neurotrauma 34, 436-443. doi: 10.1089/neu.2016.4452

Palazzo, E., Romano, R., Luongo, L., Boccella, S., De Gregorio, D., Giordano, M. E., et al. (2015). MMPIP, an mGluR7-selective negative allosteric modulator, alleviates pain and normalizes affective and cognitive behavior in neuropathic mice. Pain 156, 1060-1073. doi: 10.1097/j.pain.0000000000000150

Paxinos, G., and Franklin, K. B. (2004). The Mouse Brain in Stereotaxic Coordinates. Houston, TX: Gulf professional publishing.

Schonhofen, P., Bristot, I. J., Crippa, J. A., Hallak, J. E. C., Zuardi, A. W., Parsons, R. B., et al. (2018). Cannabinoid-based therapies and brain development: potential harmful effect of early modulation of the endocannabinoid system. CNS Drugs 32, 697-712. doi: 10.1007/s40263-018-0550-4 
Schurman, L. D., and Lichtman, A. H. (2017). Endocannabinoids: a promising impact for traumatic brain injury. Front. Pharmacol. 8:69. doi: 10.3389/fphar. 2017.00069

Schwarzbold, M., Diaz, A., Martins, E. T., Rufino, A., Amante, L. N., Thais, M. E., et al. (2008). Psychiatric disorders and traumatic brain injury. Neuropsychiatr. Dis. Treat. 4, 797-816.

Shohami, E., Cohen-Yeshurun, A., Magid, L., Algali, M., and Mechoulam, R. (2011). Endocannabinoids and traumatic brain injury. Br. J. Pharmacol. 163, 1402-1410. doi: 10.1111/j.1476-5381.2011. 01343.x

Vialou, V., Bagot, R. C., Cahill, M. E., Ferguson, D., Robison, A. J., Dietz, D. M., et al. (2014). Prefrontal cortical circuit for depression- and anxietyrelated behaviors mediated by cholecystokinin: role of deltafosb. J. Neurosci. 34, 3878-3887. doi: 10.1523/JNEUROSCI.1787-13.2014

Vigano, D., Guidali, C., Petrosino, S., Realini, N., Rubino, T., Di Marzo, V., et al. (2009). Involvement of the endocannabinoid system in phencyclidine-induced cognitive deficits modelling schizophrenia. Int. J. Neuropsychopharmacol. 12, 599-614. doi: 10.1017/S1461145708009371
Woodcock, T., and Morganti-Kossmann, C. (2013). The role of markers of inflammation in traumatic braininjury. Front. Neurol. 4:18. doi: 10.3389/fneur. 2013.00018

Conflict of Interest Statement: RR is Enecta Group staff. CB is supported by a grant provided by Enecta Group. The experiments were not supported by Enecta.

The remaining authors declare that the research was conducted in the absence of any commercial or financial relationships that could be construed as a potential conflict of interest.

Copyright (c) 2019 Belardo, Iannotta, Boccella, Rubino, Ricciardi, Infantino, Pieretti, Stella, Paino, Marabese, Maisto, Luongo, Maione and Guida. This is an open-access article distributed under the terms of the Creative Commons Attribution License (CC BY). The use, distribution or reproduction in other forums is permitted, provided the original author(s) and the copyright owner(s) are credited and that the original publication in this journal is cited, in accordance with accepted academic practice. No use, distribution or reproduction is permitted which does not comply with these terms. 